\title{
Prevalence, seasonality, and antimicrobial resistance of thermotolerant Campylobacter isolated from broiler farms and slaughterhouses in East Algeria
}

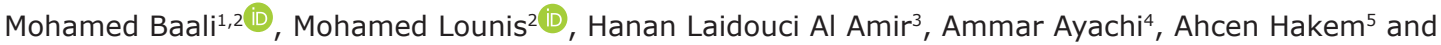 \\ Ahmed Kassah-Laouar ${ }^{6}$
}

1. Laboratory of Food Hygiene and Quality Insurance System, High National Veterinary School, Rue Issad Abbes, Oued Smar, Algiers, Algeria; 2. Department of Agroveterinary Science, Faculty of Natural and Life Sciences, University of Ziane Achour, Road of Moudjbara, Djelfa, Algeria; 3. Department of Food and Water Bacteriology, Pasteur Institute of Algeria, Road of Petit Staouéli, Dely Brahim, Algiers, Algeria; 4. Biotechnology Laboratory of Bioactive Molecules and Cellular Physiopathology, Faculty of Natural and Life Sciences, University of Batna 2, Batna, Algeria; 5. Center of Agro-pastoralism, Djelfa, Algeria; 6. Central Laboratory of Medical Biology, Anti-Cancer Center, Batna, Algeria. Corresponding author: Mohamed Baali, e-mail: drbaalimohamed@hotmail.fr Co-authors: ML: lounisvet@gmail.com, HLA: alamirab@hotmail.com,AA: aayachi54@yahoo.fr, AH: ahcenhakem@gmail.com, AK: prkassah@yahoo.fr

Received: 27-12-2019, Accepted: 11-05-2020, Published online: 28-06-2020

doi: www.doi.org/10.14202/vetworld.2020.1221-1228 How to cite this article: Baali M, Lounis M, Al Amir HL, Ayachi A, Hakem A, Kassah-Laouar A (2020) Prevalence, seasonality, and antimicrobial resistance of thermotolerant Campylobacter isolated from broiler farms and slaughterhouses in East Algeria, Veterinary World, 13(6): 1221-1228.

\begin{abstract}
Aim: The current study was carried out to determine the prevalence, seasonality, and antimicrobial profile of thermotolerant Campylobacter isolated from broiler chickens in Batna, East Algeria, from June 2016 to June 2018.

Materials and Methods: A total of 960 samples, including 480 cloacal swabs, 240 cecal contents, and 240 neck skin samples collected from 6 poultry farms and 12 slaughterhouses, were included in this study. After isolation and identification, susceptibility to seven antimicrobial agents was tested by the disk diffusion method. The seasonality of Campylobacter infection at broiler farms was statistically analyzed.

Results: The data showed that $65 \%, 55 \%$, and $70 \%$ of the cloacal swab, neck skin, and cecal content samples were contaminated with thermotolerant Campylobacter strains, respectively $(\mathrm{p}<0.05)$. Among the isolated campylobacteria, Campylobacter jejuni was the predominant species (73.5\%). Sampling season exhibited a significant impact on the prevalence of Campylobacter $(\mathrm{p}<0.01)$, with peak occurrence in summer. All of the isolates were susceptible to gentamicin and resistant to ampicillin and amoxicillin/clavulanic acid, while $83.3 \%$ of them were resistant to erythromycin. Interestingly, 16 different resistance profiles were noted, with the combination of "ampicillin, amoxicillin/clavulanic acid, chloramphenicol, erythromycin, and tetracycline" being the most common, identified in $20.7 \%$ of isolated strains.
\end{abstract}

Conclusion: This study demonstrates the presence of a high contamination rate of multidrug-resistant Campylobacter in farms and slaughterhouses in East Algeria. These findings underscore the need to apply strict control measures to avoid any associated public health hazard among Algerian consumers. This initial finding of the contamination of poultry with this zoonotic pathogen in East Algeria suggests the value of periodic comprehensive evaluation of associated disease in poultry as well as in humans in this region.

Keywords: antimicrobial resistance, broilers, poultry farms, slaughterhouses, thermotolerant Campylobacter.

\section{Introduction}

Campylobacter species, Campylobacter jejuni, Campylobacter coli, Campylobacter lari, and Campylobacter upsaliensis, are principally foodborne zoonotic pathogens frequently isolated from a variety of animal species such as poultry and cattle [1]. These pathogens threaten public health globally and are considered the most common bacteria inducing gastroenteritis in humans. They can be fatal in very young children and immunosuppressed patients. The

Copyright: Baali, et al. Open Access. This article is distributed under the terms of the Creative Commons Attribution 4.0 International License (http://creativecommons.org/licenses/by/4.0/), which permits unrestricted use, distribution, and reproduction in any medium, provided you give appropriate credit to the original author(s) and the source, provide a link to the Creative Commons license, and indicate if changes were made. The Creative Commons Public Domain Dedication waiver (http://creativecommons.org/ publicdomain/zero/1.0/) applies to the data made available in this article, unless otherwise stated. majority of campylobacteriosis cases are caused by C. jejuni and C. coli, accounting for $90 \%$ and $5-10 \%$ of cases, respectively [2].

Among animals eaten by humans, poultry is a major source of human campylobacteriosis, where both the handling and the consumption of improperly cooked poultry meat were identified as major risk factors for infection [3]. Poultry usually becomes infected at farms; however, little is known about the sources of infection and possible predisposing factors. In addition, cross-contamination of chicken carcasses with Campylobacter was documented mainly at the scalding and evisceration stages [4]. This represents a public health concern to poultry consumers. Compounding the risk further is the increasing resistance to fluoroquinolones, the most common treatment of campylobacteriosis in humans and animals, among the isolates obtained from diverse sources in several countries [5]. 
Despite the significance of this problem and the major economic and dietary roles of poultry, to the best of our knowledge, no reports were published about the situation regarding campylobacteriosis in poultry or other food products in East Algeria. Therefore, the current study was carried out to determine the prevalence of thermotolerant Campylobacter in broiler farms and slaughterhouses located in Batna region (East Algeria) and to investigate the possible effect of the season on the rate of Campylobacter infection at broiler chicken farms in this area. The antimicrobial profile of Campylobacter isolates obtained in this study was also explored.

\section{Materials and Methods \\ Ethical approval}

In this study, we used broiler cloacal swabs, samples from cecum and neck skin of broiler carcasses. Therefore, no ethical approval was needed.

\section{Sample collection}

From June 2016 to June 2018, 960 samples were collected from 6 broiler farms and 12 slaughterhouses randomly chosen in the region of Batna (East Algeria). The poultry farms were located in rural areas and contained broiler houses with a livestock capacity ranging from 4000 to 8000 animals reared in a single band until slaughter. The visited slaughterhouses were located in urban areas, and their processing capacity ranged from 600 to $1200 \mathrm{birds} / \mathrm{h}$. All farms exhibited similar breeding and biosecurity/biosafety protocols.

In terms of the total samples, 480 cloacal swabs were obtained at the farms from broiler flocks 1-2 days prior moving to the slaughterhouse (80 samples from each broiler farm divided into 20 samples for each season), 240 cecal samples were taken after the evisceration of chickens, and 240 fresh broiler chicken neck skin samples were collected at the end of the slaughtering chain. For each slaughterhouse, a single visit was performed early in the morning. Neck skin and cecal content samples were collected from the same slaughter batch and placed in sterile plastic bags and sterile plastic pots, respectively. All samples were placed inside an isothermal cool box at $4{ }^{\circ} \mathrm{C}$ and transported immediately to the Microbiology Laboratory, University Hospital of Batna, where they were processed within 3-4 h.

To monitor the fluctuations of Campylobacter colonization at farms throughout the year, samples from different seasons were included in this study: Summer (June, July, and August), fall (September, October, and November), winter (December, January, and February), and spring (March, April, and May).

\section{Isolation and identification}

The standard protocol of NF ISO 0272-1: 1995 [6] published by the International Organization for Standardization (ISO) and World Organization for Animal Health recommendations [7] were employed for the isolation and identification of thermotolerant
Campylobacter from all samples. All of Campylobacter cultures (enrichment, isolation, identification, and antimicrobial susceptibility testing) were performed under microaerobic conditions $\left(5 \% \mathrm{O}_{2}, 10 \% \mathrm{CO}_{2}\right.$, and $85 \% \mathrm{~N}_{2}$ ) generated using an anaerobic jar containing a gas generating CampyGen ${ }^{\mathrm{TM}}$ reagents (Oxoïd, UK).

For the research on Campylobacter from swabs and cecal contents, each sample was plated directly on Karmali medium (Oxoïd, UK) followed by incubation for $48 \mathrm{~h}$ at $42^{\circ} \mathrm{C}$. For neck skin samples, $10 \mathrm{~g}$ of sample was homogenized in $90 \mathrm{~mL}$ of Preston's enrichment broth (Oxoïd, UK) and maintained at $42^{\circ} \mathrm{C}$ for $24 \mathrm{~h}$ before isolation on Karmali agar. Then, the Karmali plates were streaked with one loopful of Preston broth and incubated at $42^{\circ} \mathrm{C}$ for $48 \mathrm{~h}$ in a microaerophilic atmosphere. The plates were checked daily for a total of 5 days for Campylobacter, which typically appear as gray, moist flat spreading colonies. If a second incubation was necessary, new generators were used. C. jejuni (ATCC $\left.{ }^{\circledR} 29428\right)$ and C. fetus $\left(\right.$ ATCC $\left.^{\circledR} 27374\right)$ were used as control strains.

Suspicious colonies were identified by their spreading character and mucoid appearance. Gramnegative bacilli, with spiral morphology and typically high motility with a characteristic corkscrew-like movement, catalase positive, oxidase positive, which did not show growth at $25^{\circ} \mathrm{C}$, were presumed to be thermotolerant Campylobacter in the preliminary identification.

Presumptive Campylobacter colonies were subcultured on Columbia agar (Bio-Rad, France) with 5\% horse blood (IPA: Institut Pasteur d'Algérie) and biotyped using a biochemical test on Triple Sugar Iron agar (Oxoïd, UK) of the selective hippurate hydrolysis (Remel, USA) (only C. jejuni is hippurate positive). Furthermore, all isolates were tested for their susceptibility to nalidixic acid $(30 \mu \mathrm{g})$ and cephalothin $(30 \mu \mathrm{g})$ (Bio-Rad, France) on Mueller-Hinton agar (Oxoïd, UK) with 5\% defibrinated horse blood and $\beta$-nicotinamide adenine dinucleotide ( $\beta$-NAD) (MH-F), taking into consideration, the emergence of strains resistant to nalidixic acid.

\section{Antibiotic sensitivity test}

The disk diffusion assay was performed in accordance with the method described by the antibiogram committee of the "French Society of Microbiology" CA-SFM/2014. All isolates were tested for their susceptibility to the following antibiotics: Amoxicillin/ clavulanic acid $(20 / 10 \mu \mathrm{g})$, ampicillin $(10 \mu \mathrm{g})$, erythromycin (15 IU), tetracycline (30 IU), gentamicin $(10 \mu \mathrm{g})$, ciprofloxacin $(5 \mu \mathrm{g})$, and chloramphenicol $(30 \mu \mathrm{g})$ (Bio-Rad, France).

From a pure culture of $18-24 \mathrm{~h}$, the bacterial suspension was adjusted to match the $0.5 \mathrm{McF}$ arland turbidity standard. A sterile swab was immersed into the adjusted suspension and then seeded by swabbing onto the entire surface of Mueller-Hinton agar supplemented with $5 \%$ defibrinated horse blood and $\beta$-NAD 
(MH-F). After streaking, the inoculum was dried for 5-10 min, and four antimicrobial disks were placed onto the surface of the plate. The plates were incubated at $37^{\circ} \mathrm{C}$ for $24 \mathrm{~h}$ under a microaerophilic atmosphere. Inhibition zones were measured by a caliper, and diameters were interpreted as recommended by the Antibiogram Committee of the French Society of Microbiology [8]. C. jejuni ATCC 33560 and C. coli ATCC 33876 were used as control strains.

\section{Statistical analysis}

All of the data collected within the present study were analyzed using SPSS 20.0 software (IBM Corp., NY, USA). Chi-squared test ( $\chi^{2}$ test) was used to compare the prevalence of thermotolerant Campylobacter in samples between the farms, the prevalence of isolates according to the sampling season, and the antimicrobial resistance of the isolated strains. Data were considered as significant when $\mathrm{p} \leq 0.05$ was obtained.

\section{Results}

Total prevalence of thermotolerant Campylobacter

In this study, thermotolerant Campylobacter strains were isolated at high prevalence $(63.7 \%)$ in all analyzed samples, varying from $65 \%(312 / 480)$ in farms to $62.5 \%(300 / 480)$ in slaughterhouses. More precisely, this bacterium was isolated in 55\% (132/240) of neck skin samples, $65 \%(312 / 480)$ of cloacal swabs, and $70 \%$ (168/240) of cecal contents (Table-1). The difference between the total prevalence of farms (A,B,C,D,E,F) is not significant $(\mathrm{P}=0.16)$ as shown in Table-2.

Species distribution of thermotolerant Campylobacter isolated from broiler farms and slaughterhouses

Our results showed that, out of the 612 strains identified as belonging to the Campylobacter genus, $450(73.5 \%)$ were identified as $C$. jejuni, including 10 resistant and 440 sensitive to ANC, 147 (24\%) as
C. coli (all strains sensitive to ANC), and $5(0.8 \%)$ as C. upsaliensis sensitive to ANC and cephalothin. The $10(1.6 \%)$ remaining strains were ANC-resistant C. lari or C. coli (Table-1).

Overall, C. jejuni appeared to be more common in cloacal swabs and cecal contents than in neck skin, while $C$. coli was isolated at a higher rate in neck skin than in cecal contents and cloacal swabs. Finally, C. lari and C. upsaliensis were isolated with a low prevalence in all samples.

\section{Seasonal variations at farm level}

In this study, we also attempted to establish the relationship between the prevalence of thermotolerant Campylobacter and the sampling season. Our results showed that Campylobacter was more frequently isolated in the summer months $(94.2 \%)$ than in the other seasons $(p<0.05)$. However, the lowest prevalence was recorded in winter $(38.3 \%)$. The difference in prevalence among the seasons was highly significant $(p<0.001)$ (Table-2). In addition, the difference in the prevalence of Campylobacter among the six farms in the same season was not significant $\left(P_{\text {summer }}=0.76\right.$, $P_{\text {fall }}=0.64, P_{\text {winter }}=0.18$, and $\left.P_{\text {spring }}=0.81\right)$ (Table-2).

\section{Antibiotic susceptibility of isolated strains}

All of the strains were tested for their susceptibility to seven antibiotics (Table-3). The results showed that all of the strains were resistant to ampicillin and amoxicillin/clavulanic, while all of them were susceptible to gentamycin. High levels of resistance to erythromycin $(83.3 \%)$ and tetracycline $(66.2 \%)$ were also observed. In addition, medium levels of resistance to ciprofloxacin $(46.7 \%)$ and chloramphenicol $(52.6 \%)$ were shown.

No significant differences in resistance to the same antibiotic were observed between the strains

Table-1: Species distribution of Campylobacter isolated from broiler farms and slaughterhouses.

\begin{tabular}{|c|c|c|c|c|c|}
\hline $\begin{array}{l}\text { Species } \\
\text { samples }\end{array}$ & $\begin{array}{c}\text { Campylobacter } \\
\text { jejuni }(\%)\end{array}$ & $\begin{array}{c}\text { Campylobacter } \\
\text { coli }(\%)\end{array}$ & $\begin{array}{c}\text { Campylobacter lari or } \\
\text { Campylobacter coli } \\
\text { resistant to ANC (\%) }\end{array}$ & $\begin{array}{l}\text { Campylobacter } \\
\text { upsaliensis (\%) }\end{array}$ & $\begin{array}{c}\text { Prevalence (positive } \\
\text { sample/examined } \\
\text { samples }(\%)\end{array}$ \\
\hline Cloacal swabs & $250(80.1)$ & $57(18.3)$ & $3(1)$ & $2(0.6)$ & $312 / 480(65)$ \\
\hline Ceacal contents & $125(74.4)$ & $37(22.0)$ & $4(2.4)$ & $2(1.2)$ & $168 / 240(70)$ \\
\hline Neck skin & $75(56.8)$ & $53(40.1)$ & $3(2.3)$ & $1(0.7)$ & $132 / 240(55)$ \\
\hline Total & $450(73.5)$ & $147(24.0)$ & $10(1.6)$ & $5(0.8)$ & $612 / / 960(63.7)$ \\
\hline
\end{tabular}

Table-2: Effect of seasonal variations on the prevalence of thermotolerant Campylobacter in broiler farms.

\begin{tabular}{|c|c|c|c|c|c|c|}
\hline Seasons farms & $\begin{array}{c}\text { Summer }+ \\
\text { (prevalence) } \\
(\%)\end{array}$ & $\begin{array}{c}\text { Autumn + } \\
\text { (prevalence) } \\
(\%)\end{array}$ & $\begin{array}{c}\text { Winter + } \\
\text { (prevalence) } \\
(\%)\end{array}$ & $\begin{array}{c}\text { Spring + } \\
\text { (prevalence) } \\
(\%)\end{array}$ & $\begin{array}{c}\text { Total }+ \\
\text { (prevalence) } \\
(\%)\end{array}$ & $\begin{array}{l}\text { p-value } \\
\left.\text { ( } \chi^{2} \text { test }\right)\end{array}$ \\
\hline $\bar{A}$ & $20(100)$ & $16(80)$ & $4(20)$ & $12(60)$ & $52(65)$ & 0.16 \\
\hline B & $20(100)$ & $15(75)$ & $12(60)$ & $10(50)$ & $57(71.5)$ & \\
\hline $\mathrm{C}$ & $17(85)$ & $14(70)$ & $8(40)$ & $10(50)$ & $49(61.2)$ & \\
\hline D & $18(90)$ & $16(80)$ & $8(40)$ & $10(50)$ & $52(65)$ & \\
\hline $\mathrm{E}$ & $20(100)$ & $14(70)$ & $8(40)$ & $12(60)$ & $54(67.5)$ & \\
\hline $\mathrm{F}$ & $18(90)$ & $14(70)$ & $6(30)$ & $10(50)$ & $48(60)$ & \\
\hline Total & $113(94.2)$ & $89(74.2)$ & $46(38.3)$ & $64(53.3)$ & $312(65)$ & \\
\hline $\mathrm{p}$-value ( $\chi^{2}$ test) & 0.76 & 0.64 & 0.18 & 0.81 & & \\
\hline $\mathrm{p}$-value ( $\chi^{2}$ test) & & & $<0.01$ & & & \\
\hline
\end{tabular}


isolated from cloacal swabs, cecal contents, and neck skin ( $p>0.05)$, but resistance rates among antibiotics used for the same type of sample showed a significant difference $(\mathrm{p}<0.05)$. Moreover, all isolates showed multidrug resistance to antibiotics (resistance to two antibiotics or more). More precisely, $0.3 \%$ (2/612), 4.9\% (30/612), 43.9\% (269/612), 47.2\% $(289 / 612)$, and $3.6 \%(22 / 612)$ were resistant to 2,3 , 4,5 , and 6 antibiotics, respectively. Indeed, 16 different resistance profiles were later defined. The results showed that the combination "ampicillin-amoxicillin/ clavulanic acid-erythromycin-tetracycline-chloramphenicol" was the most common profile among the campylobacteria, which was identified in $20.7 \%$ of the obtained isolates (Table-4).

\section{Discussion}

\section{Thermotolerant Campylobacter prevalence}

In this study, a total number of 960 samples were analyzed for the presence of thermotolerant Campylobacter. Bacteriological analysis of samples demonstrated that thermotolerant Campylobacter is widespread in East Algeria in both cecal contents and cloacal swabs of broilers, with a concerningly high rate of contaminated carcasses. This confirmed the results of the previous studies in Algeria [9].

\section{Thermotolerant Campylobacter prevalence in broiler farms}

In this study, a prevalence rate of thermotolerant Campylobacter of $65 \%$ was found among the cloacal swabs sampled from broiler farms. This is similar to the rate of $67.7 \%$ reported in North Ireland [10], but higher than $38.1 \%$ estimated in South Spain [11]. Conversely, the prevalence rate assessed in the present study is lower than those obtained in several reported studies, varying from $82.9 \%$ [12] to $91 \%$ [13].

The relatively high prevalence of Campylobacter observed in our study can probably be explained by the use of the swabbing technique, which allows scraping of the cloacal mucosa [14], as well as the use of Karmali medium, which shows along with the mCCDA medium the highest yield not only in the recovery of thermotolerant Campylobacter but also in the removal of competitive flora [15].

Although little information is available on the prevalence of Campylobacter in developing countries, our results are consistent with those reported in Senegal (63\%) [16]. However, Gharbi et al. and Abushahba et al. reported lower prevalence rates of $22.4 \%$ and $23.5 \%$ in North Tunisia and Upper Egypt, respectively $[17,18]$. Furthermore, the rates previously reported in Algeria vary from $12 \%$ to $96 \%[19,20]$.

Table-3: Antimicrobial resistance rates of thermotolerant Campylobacter isolated strains.

\begin{tabular}{|c|c|c|c|c|c|c|c|c|}
\hline Resistant strain source & Profile & AM & AMC & TE & CIP & $\mathbf{E}$ & GM & C \\
\hline $\begin{array}{l}\text { Resistant strain from neck } \\
\text { skin }\end{array}$ & No $(\%)$ & $132(100)$ & $132(100)$ & $88(66.6)$ & $61(46.2)$ & $109(82.6)$ & $0(00)$ & $69(52.3)$ \\
\hline $\begin{array}{l}\text { Resistant strains from cecal } \\
\text { contents }\end{array}$ & No $(\%)$ & $168(100)$ & $168(100)$ & $113(67.3)$ & $82(48.8)$ & $142(84.5)$ & $0(00)$ & $83(49.4)$ \\
\hline $\begin{array}{l}\text { Resistant strains from } \\
\text { cloacal swabs }\end{array}$ & No $(\%)$ & $312(100)$ & $312(100)$ & $204(65.4)$ & $143(45.8)$ & $259(83)$ & $0(00)$ & $170(54.5)$ \\
\hline $\begin{array}{l}\text { Resistant strains total } \\
\text { p-value }\end{array}$ & No $(\%)$ & $\begin{array}{c}612(100) \\
p>0.05\end{array}$ & $\begin{array}{c}612(100) \\
p>0.05\end{array}$ & $\begin{array}{c}405(66.2) \\
p>0.05\end{array}$ & $\begin{array}{c}286(46.7) \\
p>0.05\end{array}$ & $\begin{array}{c}510(83.3) \\
p>0.05\end{array}$ & $\begin{array}{c}0(00) \\
p>0.05\end{array}$ & $\begin{array}{c}322(52.6) \\
p>0.05\end{array}$ \\
\hline
\end{tabular}

No=Number, $\mathrm{AM}=$ Ampicillin, $\mathrm{AMC}=$ Amoxicillin/clavulanic acid, $\mathrm{C}=$ Chloramphenicol, CIP=Ciprofloxacin, $\mathrm{E}=\mathrm{Erythromycin,}$ $\mathrm{G}=$ Gentamicin, $\mathrm{TE}=$ Tetracycline. $\mathrm{p}$-value: Value for the antimicrobial resistance difference between the strains isolated from feces, cecal content and those isolated from neck skin samples to the same antibiotic

Table-4: Resistance pattern profiles of isolated thermotolerant Campylobacter strains.

\begin{tabular}{|c|c|c|c|}
\hline Associated resistances to & Resistance pattern profiles & Number of strain & Number of total (\%) \\
\hline \multirow[t]{2}{*}{ Two antibiotics } & AM, AMC & 2 & $2(0.3)$ \\
\hline & $A M, A M C, E$ & 5 & \\
\hline \multirow[t]{5}{*}{ Three antibiotics } & $A M, A M C, C$ & 5 & $30(4.9)$ \\
\hline & AM, AMC, CIP & 8 & \\
\hline & AM, AMC, TE & 12 & \\
\hline & $A M, A M C, E, C$ & 35 & \\
\hline & AM, AMC, C, TE & 27 & \\
\hline \multirow[t]{6}{*}{ Four antibiotics } & $\mathrm{AM}, \mathrm{AMC}, \mathrm{E}, \mathrm{TE}$ & 113 & 269 (43.9) \\
\hline & AM, AMC, E, CIP & 75 & \\
\hline & AM, AMC,TE,CIP & 12 & \\
\hline & $A M, A M C, C, C I P$ & 7 & \\
\hline & AM, AMC, C, E, TE & 127 & \\
\hline & AM, AMC, C, E, CIP & 70 & \\
\hline \multirow[t]{2}{*}{ Five antibiotics } & AM, AMC, C, TE, CIP & 29 & $289(47.2)$ \\
\hline & AM, AMC, TE, CIP, E & 63 & \\
\hline Six antibiotics & AM, AMC, C, TE, E, CIP & 22 & $22(3.6)$ \\
\hline
\end{tabular}

$\mathrm{AM}=$ Ampicillin, $\mathrm{AMC}=$ Amoxicillin/clavulanic acid, $\mathrm{C}=$ Chloramphenicol, CIP=Ciprofloxacin, $\mathrm{E}=$ Erythromycin, $\mathrm{G}=$ Gentamicin, TE=Tetracycline 
In this survey, the pathogen was detected at all of the 24 farms, indicating widespread contamination. This finding is supported by the fact that horizontal transmission between birds occurs rapidly (usually within 1-2 weeks), and it is enhanced by fecal excretion and coprophagy of chickens [21].

Finally, it should be noted that the differences in the prevalence of thermotolerant Campylobacter found between different studies are likely to be related to a number of factors, such as geographical location [22], sample size, culture methods [23], and age of the subjects [24].

\section{Thermotolerant Campylobacter prevalence in slaughterhouses}

Our study showed a high prevalence of Campylobacter in cecal and neck skin samples. Our findings on the prevalence of Campylobacter in cecal samples are in agreement with those in a German study in which a similar prevalence $(70 \%)$ was found [25], but lower than those reported in Algeria (98\%) [9] and Grenada (93.5\%) [26]. The intestinal carriage is attributed to the adaptation of these enteric bacteria to survival in mucus of the digestive tract [27]. This disparity in the rate of contamination with Campylobacter among countries might be due to differences in sampling schemes, analytical methods, and ages of the birds.

We recovered Campylobacter from 55\% of neck skin samples. This is similar to the prevalence of $60.8 \%$ reported by Kovalenko et al. in two Latvian broiler chicken slaughterhouses [28]. However, it is higher than the prevalence rates of $24.4 \%$ and $27.4 \%$ reported in Switzerland and Sri Lanka, respectively [29,30]. In Algeria, our finding is higher than the reported prevalence of $15.7 \%$ [31] but lower than the rate of $80 \%$ reported by Messad et al. [9].

The rates of Campylobacter contamination vary widely among countries. In a study by Garin et al., in five major cities located on four continents (Dakar, Yaounde, Noumea, Antananarivo, and Ho Chi Minh City), a range of $15.3 \%-96.7 \%$ was detected, with an average contamination rate of $65.5 \%$ [32].

In agreement with Frediani-Wolf et al. [28], our study revealed a higher level of Campylobacterpositive cecal samples than for the neck skin samples. This finding was further supported by Baré et al. [33] who reported that, among the examined chicken parts, neck skin was the most contaminated by Campylobacter.

In slaughterhouses, contamination of neck skin could be directly related to ruptured viscera of the same animal and/or to cross-contamination throughout the slaughtering process, perhaps during the evisceration step [34]. Although this evisceration was described as a critical step for Campylobacter contamination of carcasses [35], an increase of contamination is not always observed [36].

The nature of slaughter processing makes preventing cross-contamination of negative batches by positive batches impossible [29]. Indeed, the surfaces of carcasses from a Campylobacter-free flock were shown to potentially be contaminated when processed after an infected batch of birds due to the pathogen's ability to survive in water, in aerosols, and on equipment [35]. The traditional character of the visited slaughterhouses with inappropriate sites for evisceration could explain the high rate of contamination in neck skin samples.

\section{Species distribution}

Phenotypic characterization of Campylobacter isolates showed that poultry are colonized primarily by $C$. jejuni, followed by $C$. coli, and rarely by other species. These results are in agreement with the previous studies in the Netherlands [37] and Tunisia [17]. However, C. coli was isolated at a higher rate than C. jejuni in other studies in Egypt [38] and Ecuador [39]. The selective media and incubation temperatures used in this study are more efficient for the isolation of C. jejuni and C. coli than for other species [40], which raises questions about the validity of our findings on the other strains (C. lari and C. upsaliensis) and indicates the need for further molecular confirmation.

\section{Seasonal variations at farm level}

The prevalence of Campylobacter in this study showed seasonal variation. The prevalence was high in summer and fall. Similarly, seasonal variation in Campylobacter colonization of broilers with a peak in the warmer periods of the year was reported $[41,42]$. However, no seasonal variation of Campylobacter colonization was found in another study from Great Britain [13].

The definitive reasons for the seasonal variation associated with Campylobacter are unknown. However, possible associations between the pathogen's survival and the temperature [43] and/or the widespread availability of additional reservoirs and mechanical vectors for the disease [44] could explain the high prevalence in summer.

\section{Antimicrobial resistance of isolated strains}

In our study, all tested strains were susceptible to gentamycin. This reinforces the results obtained by Messad et al. in Algiers [9]. Similar findings were also reported in Grenada and Canada $[25,45]$. In fact, this finding was expected since the use of gentamycin in the poultry industry in Algeria was banned since 2006 [46]. Another reasonable explanation for this finding is the fact that gentamicin is rarely used therapeutically because of its intramuscular or subcutaneous route of administration, which is impracticable in the poultry industry [47]. However, in contrast to our finding, a high rate of gentamycin resistance $(46.9 \%$ of isolates) was reported in another study conducted in the central region of Algeria [20], indicating the possibility that gentamycin has been illegally applied there.

Conversely, a high level of resistance to erythromycin $(83.3 \%)$ was observed. This is in accordance with the results previously reported in Algeria [20]. This finding is alarming, given that this is considered as one of the first-line antibiotics against human 
campylobacteriosis. Indeed, during sampling, we observed that tylosin was the antibiotic most commonly used to control respiratory infections in the farms. This could explain the high rate of erythromycin resistance among the isolated Campylobacter strains, given that a high frequency of resistance to erythromycin usually occurs in broilers administered tylosin due to cross-resistance [48]. Moreover, Lin et al. [49] showed that the use of erythromycin in low doses over a long period (corresponding to its use as a growth factor) selects for resistant strains of Campylobacter. In contrast, a low resistance rate of $21.7 \%$ was also observed in Algeria [9,19]. In industrialized countries, resistance to erythromycin remains low [26] or even absent [50].

In this study, the rate of resistance to ciprofloxacin was estimated at $46.7 \%$. This is in agreement with the finding by Lutful-Kabir et al. in Bangladesh (45.4\%) [51] but lower than the rates of $88.1 \%$ and $100 \%$ reported in China and Latvia, respectively $[52,53]$. Furthermore, a high level (83.7\%) was also reported in Algeria [9]. The high ciprofloxacin resistance rates of Campylobacter in Algeria may be attributable to the widespread use of fluoroquinolones in both the prevention and the control of poultry diseases.

The rate of resistance to tetracycline among isolated Campylobacter strains was estimated at $66.2 \%$. This agrees with the result of Varga et al. [54]. However, a high level of such resistance of $83 \%$ was previously identified in Algeria [9,31]. The cause of these high frequencies of resistance in Algeria may be the abuse of tetracycline in broiler farms. Similarly, higher rates of tetracycline resistance were documented in Tunisia [17] and Canada [55]. The authors explained these in terms of tetracycline being used as a growth promoter in the poultry industry.

Our findings regarding the very high levels of resistance to erythromycin and tetracycline (first- and second-line therapeutic agents in human campylobacteriosis) are of great concern and should be emphasized considering that poultry is the major source of human Campylobacter infections and antimicrobial-resistant strains can easily be transmitted to humans through the food chain, potentially increasing the campylobacteriosis burden [50].

Although resistance to chloramphenicol is very rare in Campylobacter and despite the prohibition of the use of chloramphenicol in Algeria since 2006, the rate of resistance to it in our isolates was estimated at $55.3 \%$. This is very high compared with those reported in the previous studies, in which there was no or only low resistance $[9,26,56,57]$, suggesting that Campylobacter generally remains susceptible to this antimicrobial.

The rate of resistance to ampicillin (100\%) was relatively consistent with the findings of Guessoum et al., in Algeria, who reported a rate of $81.2 \%$ [19]. However, this rate is far higher than the rate of $7 \%$ reported in Iran [56]. These high rates of resistance of
Campylobacter strains to ampicillin are thought to be related to the production of beta-lactamases [58].

The same rate of resistance $(100 \%)$ was also recorded for amoxicillin/clavulanic acid, which is consistent with the previous study [57]. In contrast, lower rates were previously obtained in Algeria, varying from $27 \%$ to $46.8 \%$ [9,31].

All of our isolates were multidrug-resistant, which is in agreement with the findings of Messad et al. in Algeria [9]. The high prevalence of multidrug-resistant Campylobacter in broilers is alarming, given the fact that contaminated poultry meat is the major source of human Campylobacter infections.

Foodborne transmission of antibiotic-resistant Campylobacter to humans poses a threat to people by limiting the therapeutic choice of antibiotic and compromises the clinical treatment of human campylobacteriosis. Thus, prudent measures for antimicrobial usage and active surveillance should be established to reduce the prevalence and spread of antimicrobial-resistant Campylobacter.

\section{Conclusion}

The current study provides the first report about the spread of Campylobacter among poultry in East Algeria. Overall, the intestinal carriage and neck skin contamination rates in this study demonstrated high levels of contamination of Campylobacter in both broiler farms and slaughterhouses, which peaked in the summer. This study showed that antimicrobial resistance is highly prevalent in the poultry Campylobacter isolates, most of which are resistant to multiple antimicrobial agents. An alarming rate of resistance $(83.3 \%)$ to erythromycin was reported, which is a drug recommended for the treatment of human campylobacteriosis.

Accordingly, the implementation of specific control procedures, monitoring, and preventive approaches such as HACCP from the farm through to the consumer is strongly recommended to reduce the incidence of campylobacteriosis. Therefore, constant monitoring of Campylobacter resistance patterns is required, and the use of antibiotics in poultry meat production should be restricted and systematically controlled in Algeria.

\section{Authors' Contributions}

MB conceived, designed the study, and drafted the manuscript under the supervision of $\mathrm{AK}$ and $\mathrm{AA}$. $\mathrm{MB}$ and $\mathrm{ML}$ designed the experiment protocol under the supervision of AK and HLA. MB collected and analyzed samples. MB, ML, and AH did the statistical analysis. $\mathrm{MB}$ and $\mathrm{ML}$ revised the manuscript under the supervision of AK and AA. All authors read and approved the final manuscript.

\section{Acknowledgments}

The authors express gratitude to the Ministry of Higher Education and Scientific Research of Algeria for the facilitation of the laboratories and the use of equipment (Microbiology Laboratory of the CHU from 
Batna and Institute Pasteur, Algeria). The authors are thankful to the Microbiology team of the Department of Food and Water Bacteriology, Pasteur Institute of Algeria, for providing necessary help during this study. The authors did not receive any funds for this study.

\section{Competing Interests}

The authors declare that they have no competing interests.

\section{Publisher's Note}

Veterinary World remains neutral with regard to jurisdictional claims in published institutional affiliation.

\section{References}

1. Stanley, K. and Jones, K. (2003) Cattle and sheep farms as reservoirs of Campylobacter. J. Appl. Microbiol., 94(Suppl.): 104-113.

2. Allos, B.M. (2001) Campylobacter jejuni infections: Update on emerging issues and trends. Clin. Infect. Dis., 32(8): 1201-1206.

3. Stern, N.J., Fedorka-Cray, P., Bailey, J.S., Cox, N.A., Craven, S.E., Hiett, K.L., Musgrove, M.T., Ladely, S., Cosby, D. and Mead, G.C. (2001) Distribution of Campylobacter spp. In selected US poultry production and processing operations. J. Food Protect., 64(11): 1705-1710.

4. Hue, O., Le Bouquin, S., Laisney, M.J., Allain, V., Petetin, I., Rouxel, S., Quesne, S., Gloaguen, P.Y., Picherot, M., Santolini, J., Salvat, G., Bougeard, S. and Chemaly, M. (2010) Prevalence of and risk factors for Campylobacter spp. Contamination. Food Microbiol., 27(8): 992-999.

5. Zhou, J., Zhang, M., Yang, W., Fang, Y., Wang, G. and Hou, F. (2016) A seventeen-year observation of the antimicrobial susceptibility of clinical Campylobacter jejuni and the molecular mechanisms of erythromycin-resistant isolates in Beijing, China. Int. J. Infect. Dis., 42(1): 28-33.

6. ISO. (1995) Microbiologie des Aliments-Méthode horizontale Pour la Recherche des Campylobacter Thermotolérants. $1^{\text {st }}$ ed. AFNOR, France. p1-15.

7. OIE. (2017) Infection with Campylobacter jejuni and Campylobacter coli. In: OIE Manual of Diagnostic Tests and Vaccines for Terrestrial Animals. Ch. 2, 9, 3. OIE, Switzerland, Geneva. p1-9.

8. CA-SFM. (2014) Recommandations 2014. Comité de l'Antibiogramme de la Société Française de Microbiologie. Available from: http://www.departement-information-medicale.com/wpcontent/uploads/2015/04/casfm_eucast v1_0_2014.pdf. Retrieved on 12-11-2019.

9. Messad, S., Hamdi, T.M., Bouhamed, R., RamdaniBouguessa, N. and Tazir, M. (2014) Frequency of contamination and antimicrobial resistance of thermotolerant Campylobacter isolated from some broiler farms and slaughterhouses in the region of Algiers. Food Control, 40(1): 324-328.

10. Oza, A.N., McKenna, J.P., McDowell, S.W.J., Menzies, F.D. and Neill, S.D. (2003) Antimicrobial susceptibility of Campylobacter spp. Isolated from broiler chickens in Northern Ireland. J. Antimicrob. Chemother., 52(2): 220-223.

11. Torralbo, A., Borge, C., Allepuz, A., Ignacio GarciaBocanegra, I., Sheppard, S.K., Perea, A. and Carbonero, A. (2014) Prevalence and risk factors of Campylobacter infection in broiler flocks from Southern Spain. Prev. Vet. Med., 114(2): 106-113.

12. Pezzotti, G., Serafin, A., Luzzi, I., Mioni, R., Milan, M. and Perin, R. (2003) Occurrence and resistance to antibiotics of Campylobacter jejuni and Campylobacter coli in animals and meat in northeastern Italy. Int. J. Food Microbiol., 82(3):281-287.
13. Evans, S.J. and Sayers, A.R. (2000) A longitudinal study of Campylobacter infection of broiler flocks in Great Britain. Prev. Vet. Med., 46(3): 209-223.

14. Kaplan, R.L., Goodman, L.J., Barrett, J.E., Gordon, M., Trenholme, V.G.M. and Landau, W. (1982) Comparison of rectal swabs and stool cultures in detecting Campylobacter fetus subsp. Jejuni. J. Clin. Microbiol., 15(5): 959-960.

15. Corry, J.E., Post, D.E., Colin, P. and Laisney, M.J. (1995) Culture media for the isolation of Campylobacters. Int. J. Food Microbiol., 26(1): 43-76.

16. Cardinale, E., Tall, F., Guèye, E.F., Cisse, M. and Salvat, G. (2004) Risk factors for Campylobacter spp. Infection in Senegalese broiler-chicken flocks. Prev. Vet. Med., 64(1): $15-25$.

17. Gharbi, M., Béjaoui, A., Ben Hamda, C., Jouini, A.,Ghedira, K., Zrelli, C., Hamrouni, S., Aouadhi, C., Bessoussa, G., Ghram, A. and Maaroufi, A. (2018) Prevalence and antibiotic resistance patterns of Campylobacter spp. Isolated from broiler chickens in the North of Tunisia. Biomed. Res. Int., 2018(1): 7.

18. Abushahba, M.F. (2018) Prevalence of zoonotic species of Campylobacter in broiler chicken and humans in Assiut governorate, Egypt. Approaches Poult. Dairy Vet. Sci., 3(4): 260-268.

19. Mouffok, F. and Lebres, E. (1992) Result of the refinement of a technique for the isolation and identification of Campylobacter from food commodities. Arch. Inst. Pasteur Alg., 58: 239-246.

20. Guessoum, M., Guechi, Z., Aigoun, F., Mahrane, S. and Hachemi, A. (2016) Campylobacter in sheep, calves and broiler chickens in the central region of Algeria: Phenotypic and antimicrobial resistance profiles. Afr. J. Microbiol. Res.,10(39): 1662-1667.

21. Jacobs-Reitsma, W.F., van de Giessen, A.W., Bolder, N.M. and Mulder, R.W. (1995) Epidemiology of Campylobacter spp. At two Dutch broiler farms. Epidemiol. Infect.,114(3): 413-21.

22. Kapperud, G., Skjerve, E., Vik, L., Hauge, K., Lysaker, A., Aalmen, I., Ostroff, S.M. and Potter, M. (1993) Epidemiological investigation of risk factors for Campylobacter colonization in Norwegian broiler flocks. Epidemiol. Infect., 111(2): 245-255.

23. Jeffrey, J.S., Tonooka, K.H. and Lozano, J. (2001) Prevalence of Campylobacter spp. From skin, crop and intestine of commercial broiler chicken carcasses at processing. Poult. Sci., 80(9): 1390-1392.

24. Berndtson, E., Emanuelson, U., Engvall, A. and DanielssonTham, M.L. (2001) A 1-year epidemiological study of Campylobacters in 18 Swedish chickens farms. Prev. Vet. Med., 26(3-4): 167-185.

25. Reich, F., Atanassova, V., Haunhorst, E. and Klein, G. (2008) The effects of Campylobacter numbers in caeca on the contamination of broiler carcasses with Campylobacter. Int. J. Food Microbiol., 127(1-2): 116-120.

26. Hariharan, H., Sharmam, S., Chikweto, A., Matthew, V. and DeAllie, C. (2009) Antimicrobial drug resistance as determined by the E-test in Campylobacter jejuni, C. coli and C. lari isolates from the ceca of broiler and layer chickens in Grenada. Comp. Immunol. Microbiol. Infect. Dis., 32(1): 21-28.

27. Megraud, F. and Bultel, C. (2004) Appréciation des risques alimentaires liés aux Campylobacters. Rapport de. In: Application au Couple Poulet/Campylobacter jejuni. AFSSA, p96. Available from: https://www.anses.fr/fr/ system/files/MIC-Ra-campylobacter.pdf. Retrieved on 17-06-2020.

28. Kovalenko, K., Roasto, M., Liepin E., Mäesaar, M. and Hörman, A. (2013) High occurrence of Campylobacter spp. In Latvian broiler chicken production. Food Control., 29(1): 188-191.

29. Frediani-Wolf, V. and Stephan, R. (2003) Resistance patterns of Campylobacter spp. Strains isolated from poultry carcasses in a big Swiss poultry slaughterhouse. Int. J. Food 
Microbiol., 89(2-3): 233-240.

30. Kottawatta, K.S.A., Van Bergen, M.A.P., Abeynayake, P., Wagenaar, J.A., Veldman, K.T. and Kalupahana, R.S. (2017) Campylobacter in broiler chicken and broiler meat in Sri Lanka: Influence of semi-automated vs. Wet market processing on Campylobacter contamination of broiler neck skin samples. Foods, 6(12): 105.

31. Amir, H.L., Mouffok, F. and Hellal, A. (2013)Campylobacter research in poultry in Algeria: Study of the antimicrobial resistance profile. Rev. Méd. Vét., 164(6): 307-311.

32. Garin, B., Gouali, M., Wouafo, M., Perchec, A.M., Ham, M.T., Ravaonindrina, N., Urbès, F., Gay, M., Diawara, A., Leclercq, A., Rocourt, J. and Pouillot, R. (2012) Prevalence, quantification and antimicrobial resistance of Campylobacter spp. On chicken neck-skins at points of slaughter in 5 major cities located on 4 continents. Int. J. Food Microbiol., 157(1): 102-107.

33. Baré, J., Uyttendaele, M., Habib, I., Depraetere, O., Houf, K. and De Zutter, L. (2013) Variation in Campylobacter distribution on different sites of broiler carcasses. Food Control., 32(1): 279-282.

34. Posch, J., Feierl, G., Wuest, G., Sixl, W., Schmidt, S., Haas, D., Reinthaler, F.F. and Marth, E. (2006) Transmission of Campylobacter spp. In a poultry slaughterhouse and genetic characterization of the isolates by pulsed-field gel electrophoresis. Br. Poult. Sci., 47(3): 286-293.

35. Figueroa, G., Troncoso, M., Lopez, C., Rivas, P. and Toro, M. (2009) Occurrence and enumeration of Campylobacter spp. During the processing of Chilean broilers. BMC Microbiol., 9(9): 1-6.

36. Rosenquist, H., Sommer, H.M., Nielsen, N.L. and Christensen, B.B. (2006) The effect of slaughter operations on the contamination of chicken carcasses with thermotolerant Campylobacter. Int. J. Food Microbiol., 108(2): 226-232.

37. Schets, F.M., Jacobs-Reitsma, W.F., van der Plaats, R.Q.J., Heer, L.K., van Hoek, A.H.A., Hamidjaja, R.A., de Roda Husman, A.M. and Blaak, H. (2017) Prevalence and types of Campylobacter on poultry farms and in their direct environment. J. Water Health, 15(6): 849-862.

38. Awadallah, M.A.I., Ahmed, H.A., El-Gedawy, A.A. and Saad, A.M. (2014) Molecular identification of $C$. jejuni and $C$. coli in chicken and humans, at Zagazig Egypt with reference to the survival of $C$. jejuni in chicken meat at refrigeration and freezing temperatures. Int. Food Res. J., 21(5): 1801-1812.

39. Vinueza-Burgos, C., Wautier, M., Martiny, D., Cisneros, M., Van Damme, I. and De Zutter, L. (2017) Prevalence, antimicrobial resistance and genetic diversity of Campylobacter coli and Campylobacter jejuni in Ecuadorian broilers at slaughter age. Poult. Sci., 96(7): 2366-2374.

40. Tazumi, A., Kakinuma, Y., Misawa, N., Moore, J.E., Millar, B.C. and Matsuda, M. (2009) Identification and characterization of intervening sequences within $23 \mathrm{~S}$ rRNA genes from more than 200 Campylobacter isolates from seven species including atypical Campylobacters. BMC Microbiol., 9(1): 256.

41. Shimaa, T.O., El-Fadaly, H.A. and Barakat, A.M.A. (2015) Public health hazard of zoonotic Campylobacter jejuni reference to Egyptian regional and seasonal variations. Res. J. Microbiol., 10(8): 343-354.

42. Sommer, H.M., BorckHøg, B., Larsen, L.S., Sørensen, A.I.V., Williams, N., Merga, J.Y., Cerdà-Cuéllar, M., Urdaneta, S., Dolz, R., Wieczorek, K., Oseke, J., David, B., Hofshagen, M., Jonsson, M., Wagenaar, J.A., Bolder, N. and Rosenquist, H. (2016) Analysis of farm specific risk factors for Campylobacter colonization of broilers in six European countries. Microb. Risk Anal., 2-3: 16-26.

43. Patrick, M.E., Christiansen, L.E., Wainø, M., Ethelberg, S., Madsen, H. and Wegener, H.C. (2014) Effects of climate on incidence of Campylobacter spp. In humans and prevalence in broiler flocks in Denmark. Appl. Environ. Microbiol., 70(12): 7474-7480.

44. Ellis-Iversen, J., Jorgensen, F., Bull, S., Powell, L., Cook, A.J. and Humphrey, T.J. (2009) Risk factors for Campylobacter colonisation during rearing of broiler flocks in Great Britain. Prev. Vet. Med., 89(3-4): 178-184.

45. Narvaez-Bravo, C., Taboada, E.N., Mutschall, S.K. and Aslam, M. (2017) Epidemiology of antimicrobial resistant Campylobacter spp. Isolated from retail meats in Canada. Int. J. Food Microbiol., 253: 43-47.

46. WorldHealthOrganization.(2008)ManueldeStandardisation de L'antibiogramme en Médecine Vétérinaire à L'échelle Nationale Selon les Recommandations de L'OMS. $4^{\text {th }}$ ed. World Health Organization, Geneva.

47. Rodrigo, S., Adesiyun, A., Asgarali, Z. and Swanston, W. (2007) Antimicrobial resistance of Campylobacter spp. Isolated from broilers in small poultry processing operations in Trinidad. Food Control, 18(4): 321-325.

48. Ladely, S.R., Harrison, M.A., Fedorka-Cray, P.J., Berrang, M.E., Englen, M.D. and Meinersmann, R.J. (2007) Development of macrolide-resistant Campylobacter in broilers administered subtherapeutic or therapeutic concentrations of tylosin. J. Food Prot., 70(8): 1945-1951.

49. Lin, J., Yan, M., Sahin, O., Pereira, S., Chang, Y.J. and Zhang, Q. (2007) Effect of macrolide usage on emergence of erythromycin-resistant Campylobacter isolates in chickens. Antimicrob. Agents Chemother., 51(5): 1678-1686.

50. Adiguzel, M.C., Sigirci, B.D., Celik, B., Kahraman, B.B., Metiner, K., Ikiz, S., Bagcigil, A.F., Seyyal, A.K. and Ozgur, N.Y. (2018) Phenotypic and genotypic examination of antimicrobial resistance in thermophilic Campylobacter species isolated from poultry in Turkey. J. Vet. Res., 62(4): 463-468

51. LutfulKabir, S.M., Suman, M.H., Amin, M.M. and Yamasaki, S. (2014) Isolation, identification and antimicrobial resistance patterns of Campylobacter species from broiler meat sold at KR market of Bangladesh Agricultural University Campus, Mymensingh. J. Agric. Food Tech., 4(4): 1-7.

52. Han, X., Zhu, D., Lai, H., Zeng, Z., Zhou, K., Han, G. and Liu, S. (2016) Prevalence, antimicrobial resistance profiling and genetic diversity of Campylobacter jejuni and Campylobacter coli isolated from broilers at slaughter in China. Food Control, 69: 160-170.

53. Kovalenko, K., Roasto, M., Santare, S., Berzins, A. and Hman, A. (2014) Campylobacter species and their antimicrobial resistance in Latvian broiler chicken production. Food Control, 46: 86-90.

54. Varga, C., Guerin, M.T., Brash, M.L., Slavic, D., Boerlin, P. and Susta, L. (2019) Antimicrobial resistance in Campylobacter jejuni and Campylobacter coli isolated from small poultry flocks in Ontario, Canada: A two-year surveillance study. PLoS One, 14(8): e0221429.

55. Guévremont, E., Nadeau, É., Sirois, M. and Quessy, S. (2006) Antimicrobial susceptibilities of thermophilic Campylobacter from humans, swine, and chicken broilers. Can. J. Vet. Res., 70(2): 81-86.

56. Zendehbad, B.B., Khayatzadeh, J. and Alipour, A. (2015) Prevalence, seasonality and antibiotic susceptibility of Campylobacter spp. Isolates of retail broiler meat in Iran. Food Control, 53: 41-45.

57. Noormohamed, A. and Fakhr, M.K. (2015) Prevalence and antimicrobial susceptibility of Campylobacter spp. In Oklahoma conventional and organic retail poultry. Open Microbiol. J., 8: 130-137.

58. Simaluiza, R.J., Toledo, Z., Ochoa, S. and Fernández, H. (2015) Resistance of Campylobacter jejuni and Campylobacter coli in chicken livers used for human consumption in Ecuador. J. Anim. Vet. Adv., 14(1): 6-9. 